\title{
Ophthalmic residents' surgical training: a study of patient perspective and attitudes in a teaching hospital in India
}

\author{
Ziya Siddiqui ${ }^{1}$, Ali Jafar Abedi ${ }^{2}$, Adeeb Alam Khan', Atika Javed Siddiqui ${ }^{3}$, \\ Gaganjeet Singh Gujral ${ }^{1}$
}

\author{
${ }^{1}$ Institute of Ophthalmology, J. N. Medical College, AMU, Aligarh, Uttar Pradesh \\ ${ }^{2}$ Department Community Medicine, J. N. Medical College, AMU, Aligarh, Uttar Pradesh \\ ${ }^{3}$ Consultant, Vision Max Eye Care Centre, Aligarh, Uttar Pradesh
}

Received: 16 December 2015

Accepted: 08 January 2016

\section{*Correspondence:}

Dr. Ali Jafar Abedi,

E-mail: alijafarabedi@gmail.com

Copyright: (c) the author(s), publisher and licensee Medip Academy. This is an open-access article distributed under the terms of the Creative Commons Attribution Non-Commercial License, which permits unrestricted non-commercial use, distribution, and reproduction in any medium, provided the original work is properly cited.

\section{ABSTRACT}

Background: An important aim of medical education is to provide sufficient surgical training to residents. Attitudes of patient toward the surgical training of residents and the impact of resident's participation on patients' perceptions of care are relatively unknown in India. We therefore undertook this study to assess patient attitudes towards resident cataract surgery training in a teaching hospital.

Methods: An anonymous survey was conducted in a teaching hospital on all patients undergoing elective cataract surgery. A questionnaire was developed with inputs from published work, modified according to local needs to record demographic information and elicits patient perspective and attitude towards resident training. Responses of patient's were graded using a 5-point Likert scale. The data was analysed using SPSS-version 19.

Results: Only $35 \%$ of surveyed patients selected the most accurate definition of a resident and teaching hospital. The majority $(63 \%)$ felt "assistance" meant that the resident would be performing parts of surgery, but not the entire procedure. $25 \%$ of patients were comfortable having a resident assist their surgery, while only $07 \%$ were comfortable with residents performing the entire surgery. Majority (58\%) agreed that residents should be involved in the surgical care. Patients demographic background had a significant association with attitudes toward resident involvement in surgery $(\mathrm{p}<0.05)$.

Conclusions: Results showed varied opinions amongst patients toward the involvement of residents in surgical care. Patient orientation on the resident education process is vital to their perceptions of care and may render them willing to participate in training if they are taken into confidence by the faculty surgeon.

Keywords: Resident, Surgical training, Attitude, Cataract

\section{INTRODUCTION}

India has emerged as the blindness capital of the world with world's largest blind population, more than half of which is avoidable blindness due to Cataract. ${ }^{1}$ Vision 2020 goals cannot be realised without increasing the cataract surgery rate and ensuring quality outcomes of such surgeries which requires maximal emphasis on cataract surgery training during residency program so that young Ophthalmologists in India are proficient in cataract surgery. Most residency program guidelines require trainees to perform a specified number of procedures before they exit the program. The training demands coupled with surgical backlog push the faculty surgeons and the resident trainees to perform ever increasing numbers of surgeries. 
However this objective is at loggerheads with the patient's rights of privacy, informed consent and choice and may compromise on the other goals of tertiary care training institutions which include ensuring highest quality eye care, financial viability, overall patient satisfaction and compliance with ethical issues. Thus, faculty surgeons in India are at a crossroads. Quality surgical care, legitimate patient rights and ethical issues and finally resident training are the available paths with diverging courses and conflicting interests.

Resident training in surgery is an important component of any academic program. The medical profession has an ethical and social obligation to educate physicians and surgeons to meet the needs of future generations of patients. $^{2}$ Surgical skills have been learned and practiced on patients for centuries as skill development requires practice in a real environment. ${ }^{3}$ In Cataract surgery there is no suitable surrogate training model that absolutely simulates the live surgery scenario. ${ }^{4}$

Informed consent has become a legal requirement before elective surgical procedures. ${ }^{5}$ Patients want information about cataract, treatment options, and chances of improvement in vision, risks of deferring the surgery and complications that may occur pre and post operatively. ${ }^{6}$ Many authors have discussed the best practices for eliciting informed consent through information leaflets, videos, personal interactions and generic proforma. ${ }^{7-11}$ However, the more contentious issue of disclosure and discussion of resident training in consent procedures has not achieved much attention, as many surgeons feel that since cataract surgery is an elective surgical procedure, detailed communication with the patients at the time of eliciting informed consent regarding the need and extent of resident participation in their care and the training objectives of the institution may lead the patient to refuse treatment and seek care elsewhere where resident training is not the mandate. They suggest evoking altruistic response from the patient regarding the need for surgical training in society without discussing specific details. ${ }^{12}$

On the other hand, the Royal College of Ophthalmologists (RCOphth) advises that the patients be told about resident involvement in surgery and the extent of their participation under supervision. ${ }^{13}$ American Academy of Ophthalmology also advises proper disclosure of identity, qualification and role of the personnel involved in patient care. ${ }^{14}$ Further in the era of Consumer grievance redressal taking centre stage in the doctor patient relationship, prior disclosure and discussion on resident participation in surgery and care will prevent or reduce future litigation by patients for breach of trust, negligence or deficiency in care and service, as most law suits in medical practice result from communication failure rather than errors. ${ }^{15}$

The big question is; how much information to the patient is enough? And who should be entrusted to accomplish this onerous task and when?
Published data on patients' perspectives and attitudes towards resident surgical training and informed consent for cataract surgery from India is scarce. We therefore decided to undertake the present study to use survey based methods to assess and measure patient's attitudes and perspectives with regards to resident training and patient care in a teaching hospital setting.

\section{METHODS}

We developed an anonymous patient survey using multiple choice questions and statements measurable on a 5 point Likert psychometric scale to assess patient's knowledge of the need, scope and extent of resident training and their attitudes towards resident participation in their cataract surgery. The development of the survey included literature search on informed consent and resident participation in surgical training and patient care. ${ }^{16-21}$ The collected information was modified to suit our specific concerns related to Ophthalmic practice in India. The survey included demographic data on age, sex, socioeconomic and educational status. Every care was taken to protect patient identity and privacy.

The survey was administered by a Medical Intern in the Outpatient service of J. N. Medical College, AMU, Aligarh between January 2013 and September 2013, after the patient was examined by attending faculty and residents and was advised surgery. Patients eligible for participation in the study were older than 18 years, having documented cataracts, scheduled to undergo elective cataract surgery in the teaching hospital and were willing to participate. Exclusion criteria included prior exposure to informed consent procedure for cataract surgery and unwillingness to participate.

We defined the following terms: cataract surgery, informed consent, teaching hospital, faculty surgeon, medical student, ophthalmology resident, assistance and performance of surgery. The questionnaire was designed to elicit the level of patient knowledge, assess the patient behaviour and measure the patient comfort in a teaching hospital environment. The participants were asked to define the terms "resident" and "assistance in surgery" and select the most appropriate person to administer informed consent in multiple choice formats with 4 options. Ten, psychometric response statements covering the entire patient information and consent procedure followed. The topics included were: whether being a patient at a teaching hospital implies resident participation in their surgical care by default; whether a standard consent form is sufficient to inform and explain resident participation/assistance in surgery; whether they prefer to have the option to choose if a resident would examine them prior to examination by a faculty surgeon; whether they were comfortable at having a resident perform a portion of their surgical procedure; whether they were comfortable at having a resident perform their entire surgical procedure; whether by allowing resident participation they are helping residents become better 
surgeons and are helping future patients who will be cared for by these residents in time; whether resident should be involved in their care and that of all patients; whether they would seek treatment elsewhere if resident participation is compulsory; whether they would agree to resident participation if given financial incentives; whether they fear refusal or deficiency in care and service if they reject resident participation; The 5 point Likert scale response options ranged from "strongly agree", "agree", "neutral", "disagree" to "strongly disagree. Survey data was reported as percentage of respondents per specific response option. Similar Likert responses (i.e., strongly agree and agree) were reported as group summation in order to reflect the participant consensus towards a particular survey statement. A response of neutral was reported as its own category, as this was not reflective of a positive or negative attitude. Statistical analysis was done with commercially available software SPSS-version 19.

\section{RESULTS}

116 consecutive patients scheduled for elective cataract surgery completed the survey. All of them confirmed to the inclusion criteria.

Table 1: Socio- demographic characteristics of studied population $(\mathrm{N}=116)$.

\begin{tabular}{|lc|}
\hline \multicolumn{1}{|l|}{ Characteristics } & \multicolumn{1}{l|}{$\mathbf{N}(\%)$} \\
\hline Religion & \multicolumn{1}{l|}{$58(50.0)$} \\
\hline Hindu & $58(50.0)$ \\
\hline Muslim & $29(25.0)$ \\
\hline Education of Head of the Family \\
\hline Illiterate & $87(75.0)$ \\
\hline Literate & \\
\hline Locality & $43(37.1)$ \\
\hline Rural & $73(62.9)$ \\
\hline Urban & $05(04.3)$ \\
\hline Social Class (Modified Prasad) & \\
\hline I & $09(07.8)$ \\
\hline II & $22(18.9)$ \\
\hline III & $30(25.8)$ \\
\hline IV & $50(43.2)$ \\
\hline V &
\end{tabular}

Question 1 asked the patients to select the most appropriate definition of a "resident trainee". Patients responded to the question as following; $30 \%$ chose option A (A medical student still in training not licensed to practice), 35\% chose option B (Licensed doctor pursuing speciality training), $20 \%$ chose option $\mathrm{C}$ (Trained doctor awaiting license to practice medicine) and $15 \%$ chose option D (Licensed doctor who has not chosen a speciality for practice). Question 2 asked the patients to define what the term assistance in surgery would mean to them if they were told that a resident will/may assist in their surgery. Responses were made as follows; $20 \%$ chose option A (A resident would be present during the surgery as an observer), 10\% chose option B (A resident would perform the operation in parts but independently), $63 \%$ chose option $\mathrm{C}$ (A resident would perform parts of the operation under supervision, and $7 \%$ chose option D (A resident would perform the whole operation under supervision). Question 3 asked patients about the most suitable person to explain the surgical procedure and seek informed consent from them. Responses were recorded as following; 62\% chose option A (Faculty surgeon), $20 \%$ chose option B (Resident), 13\% chose option C (Staff nurse) and 5\% chose option D (Neutral view, any of the above options is acceptable).

On the Likert psychometric response scale, $70 \%$ of 116 patients agreed that being a patient at a teaching hospital implied that resident trainees will be involved with all aspects of surgical care with $22 \%$ neutral and $8 \%$ negative view. $52 \%$ patients agreed that a standard generic consent proforma is all that is needed to inform and explain resident participation with $20 \%$ neutral and $28 \%$ negative view. $35 \%$ patients preferred the option of choosing whether a resident trainee would examine them prior to being seen by a faculty surgeon. 32\% patients agreed to having a resident trainee perform parts of their operation with $42 \%$ neutral and $26 \%$ negative view. Only $7 \%$ patients agreed to allow residents perform whole of their operation with $25 \%$ neutral and $68 \%$ negative view. Majority of patients at $85 \%$ agreed that they were helping residents in becoming better surgeons, and were helping future patients by allowing resident participation in their care or surgery. $58 \%$ agreed to involvement of residents in their surgical care and that of all patients in the hospital. Only $15 \%$ patients agreed to seeking care elsewhere in case of compulsory resident involvement in their care with a $65 \%$ neutral view. Similarly majority rejected the idea of financial incentives for allowing resident involvement with only $9 \%$ in agreement, $25 \%$ neutral and $66 \%$ negative view. Finally only $15 \%$ patients feared a refusal or deficiency in care and services on rejecting resident involvement with $24 \%$ neutral and $61 \%$ negative view.

The survey responses were also analysed to determine whether the responses varied according to demographic characteristics. Patients with higher socioeconomic and educational status were less likely to consent for resident assistance or performance of surgery and were more likely to seek treatment elsewhere if resident participation was compulsory with a statistically significant difference $(\mathrm{p}<0.05)$.

\section{DISCUSSION}

The extent of resident participation in elective cataract surgery in a teaching hospital has important ethical and medico legal implications for the patient and the institution alike. Prior disclosure of the purpose and method of resident participation as part of informed consent process will go a long way in allaying patient fears and would make more and more patients willing to 
allow resident participation and thus help realise the goals of medical teaching. Several studies have discussed the relationship of informed consent with resident training in general and in ophthalmic surgery and have examined the patient behavior and attitudes towards resident participation in a teaching hospital setting. ${ }^{2,12,16-21}$

Table 2: Likert psychometric response statements and the response options (\%).

\begin{tabular}{|llllll|}
\hline & $\begin{array}{l}\text { Strongly } \\
\text { agree (\%) }\end{array}$ & $\begin{array}{l}\text { Agree } \\
(\%)\end{array}$ & $\begin{array}{l}\text { Neither agrees } \\
\text { nor disagree (\%) }\end{array}$ & $\begin{array}{l}\text { Disagree } \\
(\%)\end{array}$ & $\begin{array}{l}\text { Strongly } \\
\text { disagree (\%) }\end{array}$ \\
\hline $\begin{array}{l}\text { 1. At a teaching hospital residents would be } \\
\text { involved in all aspects of surgical care. }\end{array}$ & 26 & 44 & 22 & 6 & 2 \\
\hline $\begin{array}{l}\text { 2. Standard generic consent proforma is all } \\
\text { that is needed to inform and explain resident } \\
\text { participation. }\end{array}$ & 17 & 35 & 20 & 16 & 12 \\
\hline $\begin{array}{l}\text { 3. A resident trainee would examine me prior } \\
\text { to being seen by a faculty member. }\end{array}$ & 10 & 25 & 25 & 28 & 12 \\
\hline 4. Allow resident perform parts of my operation. 6 & 26 & 42 & 22 & 4 \\
\hline $\begin{array}{l}\text { 5. Allow residents perform whole of my } \\
\text { operation. }\end{array}$ & 3 & 4 & 25 & 53 & 15 \\
\hline $\begin{array}{l}\text { 6. Help residents in becoming better surgeons } \\
\text { by allowing resident participation in my care } \\
\text { or surgery }\end{array}$ & 22 & 63 & 5 & 6 & 4 \\
\hline $\begin{array}{l}\text { 7. Involvement of residents in my surgical } \\
\text { care and that of all patients. }\end{array}$ & 16 & 42 & 12 & 21 & 9 \\
\hline $\begin{array}{l}\text { 8. Will seek care elsewhere in case of } \\
\text { compulsory resident involvement in my care }\end{array}$ & 5 & 10 & 65 & 11 & 9 \\
\hline $\begin{array}{l}\text { 9. Agreement with financial incentives for } \\
\text { allowing resident involvement. }\end{array}$ & 4 & 5 & 25 & 51 & 15 \\
\hline $\begin{array}{l}\text { 10. Fear a refusal or deficiency in care and } \\
\text { services on rejecting resident involvement. }\end{array}$ & 6 & 9 & 24 & 46 & 15 \\
\hline
\end{tabular}

Despite the growing concern towards patient attitudes and perspectives towards resident training we found that only $35 \%$ of respondents were able to select the best definition of a resident from available options in contrast with the $54 \%$ seen in the APORT study. ${ }^{20}$ Nearly two third patients at $65 \%$ chose the most appropriate explanation of the word assistance in surgery, and a similar $62 \%$ respondent felt that the faculty surgeon is the best person to elicit informed consent and disclose and explain resident involvement in their care. This is in contrast with only $26 \%$ consent being taken by faculty surgeons as reported in a nationwide survey of surgery trainers by Steeples. ${ }^{21}$ Between $52 \%$ to $70 \%$ respondents had favourable idea of informed consent and role of teaching hospital in resident training similar to the $70 \%$ awareness rate reported by Moodie et al and Wisner et al. ${ }^{4,18} \mathrm{We}$ recorded moderate level of acceptance to part performance of surgery at $32 \%$ and low level of acceptance to complete performance of surgery at $7 \%$ similar to the findings of Nguyen et al reporting only $16 \%$ acceptance of resident participation and APORT study recording $35 \%$ acceptance for assistance and $11 \%$ for performance of surgery, but much lower than the $83 \%$ and $49 \%$ acceptance of assistance and performance of surgery respectively reported by Wisner et al, 95\% acceptance of resident participation reported by Gan et al,
$67 \%$ acceptance of resident participation reported by Vallance et al and $57 \%$ acceptance of resident performance of surgery reported by Moodie et al. ${ }^{4,16-20}$ In the Likert psychometric analysis our results were similar to those seen in the APORT study largely because of the similar inclusion criteria but significant differences were seen with reference to the demographic characteristics as the APORT study did not include demographic information and the other reported studies had demographic data which was vastly different from the demographic features of our study population.

These results highlight the importance of two way communications between the patients and faculty surgeons regarding the goals of residency training and the responsibility of a teaching hospital and the need to educate patients about qualifications, responsibilities, roles and contributions of residents in a teaching environment. Formal disclosure of resident involvement by the attending faculty and discussion on the need, scope, extent and utility of such training with the patients may sensitize them to the objectives of resident training and assure them of highest level of impartial care without compromising on their ethical and legal rights or adversely affecting resident training opportunities. It is imperative to use carefully worded, uniform and 
standardized phraseology for the patient information process as suggested by the RCOphth and GMC guidelines. ${ }^{13,22}$

\section{CONCLUSION}

Our study suffers from the shortcomings of a small sample size and inclusion of only elective cataract surgery patients who often were long term patients of a faculty surgeon. Patients with prior exposure to residency system in the Outpatient service may have a more favourable response to resident surgical training. Also patients already booked to undergo surgery in the teaching institution may feel compelled to volunteer pleasing/favourable responses to the interviewer. SocioDemographic characteristics of patient's attending medical college hospitals are vastly different from those attending private consultancies or non-teaching institutions and may not be representative of the community at large. However, we have seen encouraging trends in the patient attitudes and perspectives on residency training. Further studies on larger populations with more variables are needed to establish these findings and study patient psychology in more detail to make the patient experience of seeking care in a teaching hospital environment, a comfortable, fruitful and memorable one.

Funding: No funding sources

Conflict of interest: None declared

Ethical approval: The study was approved by the Institutional Ethics Committee

\section{REFERENCES}

1. Murthy GVS, Gupta SK, John N, Vashisht P. Current estimates of blindness in India. Indian. $\mathrm{J}$ of Ophth. 2008;56(6):489-94.

2. Jones JW, McCollough LB. Consent for residents to perform surgery. J Vasc Surgery. 2002;36(3):655-6.

3. Raja AJ, Levin AV. Challenges of teaching surgery: ethical framework. World J Surgery. 2003;27(8):948-51.

4. Moodie JJ, Masoodi I, Nint N, Rubenstein M, Vernon SA. Patient attitudes towards trainee surgeons performing cataract surgery at a teaching hospital. Eye (London). 2008;22(9):1183-6.

5. Niselle $\mathrm{P}$. Informed consent. $\mathrm{N} Z$ Med J. 1993;106:331-2.

6. Elder MJ, Suter A. What patients want to know before they have cataract surgery. Br $\mathrm{J}$ of Ophth. 2004;88:331-2.

7. Kiss CG, Richter- Mueksch S, Stifter E, Diendorferradner G, Velikay- Parel M, Radner W. Informed consent and decision making by cataract patients. Arch. Of Ophthalmology. 2004;122(1):94-8.
8. Abbott RL. Informed consent in cataract surgery. Curr Opininion in Ophthalmology. 2009;20(1):52-5.

9. Cheung D, Sandramouli S. The consent of patients for cataract surgery. A prospective audit. Eye (London). 2005; 19(9):963-71.

10. Scanlan D, Siddiqui F, Perry G, Hutnik CM. Informed consent for cataract surgery. What patients do and donot understand. J Cataract \& Refractive Surgery. 2003;29(10):1904-12.

11. Brown H, Ramchandani M, Gillow JT, Tsaloumas MD. Are patient information leaflets contributing to informed consent for cataract surgery. Journal of Medical Ethics. 2004;30:218-20.

12. Thomasama DC, Pickleman J. The ethical challenges of surgical training programs. Bull. Of American College of Surgeons. 1983;68:18-23.

13. The Royal College of ophthalmologists' cataract surgery guidelines 2010. https://www.rcophth.ac.uk/wpcontent/uploads/2014/ 12/2010-SCI-069-Cataract-Surgery-Guidelines2010-SEPTEMBER-2010.pdf.

14. American academy of ophthalmology board of trustees. Informed consent: advisory opinion of the code of ethics, 2004. http://www.aao.org/about/ethics/informed consent.

15. Maroforou A, Michalodimitrakis E. Physicians liability in Ophthalmology practice. Acta Ophthalmologica Scandenevia. 2003;81:321-5.

16. Vallance JH, Ahmed M, Dhillon B. Cataract surgery and consent: recall, anxiety and attitude toward trainee surgeons preoperatively and postoperatively. J Cataract \& Refractive Surgery. 2004;30:1479-85.

17. Nguyen TN, Silver D, Arthurs B. Consent to cataract surgery performed by residents. Canadian $\mathbf{J}$ of Ophth. 2005;40:34-7.

18. Wisner DM, Quillen DA, Benderson DM, Green MJ. Patient attitudes toward resident involvement in cataract surgery. Archives of Ophthalmology. 2008;126(9):1235-9.

19. Gan KD, Rudinsky CJ, Weis E. Discussing resident participation in cataract surgery. Canadian $\mathrm{J}$ of Ophth. 2009;44:651-4.

20. Welch MJ, Mc Donnell MD. Attitudes and perspectives on Ophthalmology resident training: The APORT study series pilot study. Chicagoinet. org/ images /welch.pdf.

21. Steeples L, Smyth K, Merceica K. Consent for Cataract surgery training: A national trainers survey. Eye (London). 2012;26(5):666-70.

22. General Medical Council. GMC London; 2008. Consent: Patients and doctors making decisions together.

Cite this article as: Siddiqui Z, Abedi AJ, Khan AA, Siddiqui AJ, Gujral GS. Ophthalmic residents' surgical training: a study of patient perspective and attitudes in a teaching hospital in India. Int J Community Med Public Health 2016;3:517-22. 


\section{APPENDIX}

Multiple choice format questions were as follows;

Q.1. What do you mean by the term resident;

a.) A medical student still in training not licensed to practice.

b.) A licensed doctor pursuing speciality training.

c.) A trained doctor awaiting license to practice medicine.

d.) A licensed doctor who has not chosen a speciality for practice.

Q.2. What would assistance in surgery mean to you with reference to your cataract surgery;

a.) A resident would be present during the surgery as an observer.

b.) A resident would perform the operation in parts but independently.

c.) A resident would perform parts of the operation under supervision.

d.) A resident would perform the whole operation under supervision.

Q.3. Who is the most suitable person to explain the surgical procedure and seek informed consent;

a.) Attending physician.

b.) Resident.

c.) Staff nurse.

d.) Neutral view, any of the above options is acceptable.

Likert psychometric response statements and the response options were as follows;

Please respond to the following statements using the below rating scale by placing a number in the blank in front of each statement:

1. Strongly agree

2. Agree

3. Neutral

4. Disagree

5. Strongly disagree

- I understand that being a patient at a teaching hospital implies that residents would be involved in all aspects of surgical care.

------ I understand that a standard generic consent proforma is all that is needed to inform and explain resident participation. member.

- I prefer the option of choosing whether a resident trainee would examine me prior to being seen by a faculty

-------- I agree to allowing residents perform parts of my operation.

I agree to allowing residents perform whole of my operation.

I agree that I will be helping residents in becoming better surgeons, and will be helping future patients by allowing resident participation in my care or surgery.

------ I agree to involvement of residents in my surgical care and that of all patients in the hospital.

I would seek care elsewhere in case of compulsory resident invovement in my care.

I am not comfortable with the idea of financial incentives for allowing resident involvement.

I fear a refusal or deficiency in care and services on rejecting resident involvement. 